\title{
Why you cannot regulate for virtuous compassion.
}

This is a draft of a chapter that will be appearing (as Chapter 1) in the forthcoming Routledge book Cultivating Moral Character and Virtue in Professional Practice (2018), editor, David Carr available for pre-purchase here:

https://www.routledge.com/Cultivating-Moral-Character-and-Virtue-in-Professional-

$\underline{\text { Practice/Carr/p/book/9781138742314 }}$ 


\section{Introduction.}

Professional practice within health care undergoes constant development as demographic patterns of health and disease change and the march of medical science brings new treatments to an aging population. In recent years, and particularly in countries operating a socialised system of health care, this development is undertaken within a context of fiscal challenge characterised by large levels of debt and continuing budgetary deficit. In the UK, such challenges have resulted in what some refer to a crisis in service provision. These challenges have been particularly keen for nursing where a series of scandals of poor care have led to a lessening of confidence in the profession. As part of the response to such episodes, regulators and government have highlighted the need for compassion in care, including its inclusion in a revised professional code of conduct. Nurses are now required to treat people with compassion.

This chapter examines this development in two parts. Initially, a little detail about the events at Mid-Staffordshire NHSFT precedes an analysis of the appearance of compassion in codes and other regulatory and policy documents. In the second part, this appearance in regulatory codes is problematized on four counts. First: that the need for compassion is frequently assumed and seldom challenged; second, that compliance in quasi-legal codes requires understanding of its absence rather than its presence; third, that you cannot require people to have an emotional response; fourth, that enforced behaviour that looks like compassion is not compassionate. Attempting to require individual practitioners to treat people with compassion misunderstands both the nature of compassion and the function of codes. This is not to deny that good health care practice is or should be undertaken by compassionate practitioners; but this is best achieved through education and by providing an environment where compassionate practice can flourish.

\section{Mid Staffordshire NHSFT, and the compassion deficit in nurses}

When the history of UK nursing in the twenty first century comes to be written, the events at Mid Staffordshire NHSFT in the years 2005-2009 will be seen as of pivotal importance. Concerns about excess mortality and poor care resulted in a number of reports that failed adequately to answer criticisms or to satisfy local pressure groups. In response, Andy Burnham, the Labour Secretary of State for Health commissioned Robert Francis QC, to undertake an independent inquiry, and his first report (Francis 2010) detailed numerous incidences of poor care, and recommended that a wider enquiry be undertaken. After the 
general election of 2010 which returned the Conservative-Liberal Democrat government and a continuing period of austerity, this wider enquiry was given the legal status of public enquiry, reporting in three volumes and almost 1800 pages in January 2013 (Francis 2013). Whilst referring to the awful experiences of individual patients at the hands of individual nurses and ward teams, these volumes also detailed wider organisational and cultural issues within the NHS and health care professions.

The tension between situational and individual factors in influencing behaviour is well known and can be seen in the events at Mid-Staffordshire and elsewhere. There is no doubt that some nurses showed 'callous indifference' towards patients, but a number of situational factors which significantly contributed to events were also identified, including poor leadership, prioritising financial targets and staff shortages. In an already much cited paper Paley (2014) drew upon the social psychology literature to suggest that there was no deficit in the compassion of nurses, and that lapses in care, which more often took the form of omissions than deliberately cruel acts, could largely be explained by general busy-ness. Wellknown psychology experiments were cited in support. In one, an obviously visible man in a gorilla costume strolls across a basketball court unseen by many participants concentrating instead on counting passes (Simons and Chabris 1999). In another, seminarian students late to deliver a lecture fail to spot a man in need of assistance as they rush past (Darley and Batson, 1973). By inference, nurses 'run-ragged' by ever-increasing demands and staff shortages simply failed to see the distress of the patients.

For a lengthy paper published in a normally rather esoteric academic journal, Paley provoked a number of responses (for example, Rolfe and Gardner 2014). As well as robustly critiquing Paley's application of the psychology experiments, the responses largely accepted that there had been erosion in standards in bedside nursing care. Individual nurses just aren't as compassionate as they used to be. Explanations in terms of personal moral failure (The 'Bad Apple' - Traynor et al. 2014) find some favour with a public influenced by press coverage which tends to portray nursing as a 'troubled' profession (Girvin et al. 2016), reinforced by some scepticism about the value of graduate preparation and professional status (Gillett 2012). Politicians have also been quick to point the finger at the profession of nursing and individual nurses. For example, the Prime Minister, David Cameron was reported as saying that 'there is a real problem with nursing in our hospitals' which has been hidden to avoid rows and because people are so respectful of the work that nurses do (Kirkup and Holehouse 2012a, 2012b). He was speaking at the launch of an initiative requiring nurses to perform 
'rounds' on all patients every hour whether they need it or not; a clear example of response which sees episodes of bad care principally in terms of underperforming individuals who just need to be told what to do (Snelling 2013).

Taken together, the reports received a number of responses, including from the regulator, the Nursing and Midwifery Council [NMC](NMC 2013), who proposed, inter alia, to undertake a comprehensive review of their professional code - recognising that there is a 'need to raise awareness of, and ensure compliance with, the Code...' (NMC 2013, p.21). In fact, Robert Francis saw no need to change the Code, and had praised an earlier version. A version of the NMC Code written in 2002 was in force at the start of the period investigated (January 2005 - March 2009), and a newer version was implemented from 2008. It is worthwhile to quote the relevant paragraph in full:

The NMC's fitness to practise role is based on a Code which, like the GMC's Good Medical Practice, has the merit of clarity and simplicity. Criticisms have been suggested of the 2002 version of the NMC's Code for not making clear the priority that has to be given to patients. That criticism is unfounded. Not only is the requirement plain on a reading of the whole of The Code, it was also the product of a time when it was probably presumed that no nurse would ever think anything else was the priority. Unhappily, experiences such as that of Mid Staffordshire show that this presumption can no longer be made.

(Francis 2013 p.1040)

\section{Nursing organisations and their codes.}

Broadly speaking, there are three different functions performed by organisations operating in the environment of professional health care (International Council of Nurses 2015). First, the promotion of professional practice, which involves writing guidelines and other promotional and educational material, organising conferences and lobbying government. Second, regulation protects the public by enforcing minimum standards, including maintenance of a register of individuals permitted to practice. Entry to the register is controlled by validation of educational courses, and individual nurses whose practice is deficient can be removed from the register through fitness to practice procedures. Third, the socioeconomic welfare of nurses requires negotiating pay and conditions of work. Although there is some overlap between these functions, there is also clearly some tension: for example, nurses accused of malpractice by the regulator are often represented by their union. Organisations tend to undertake one of these roles, but in some cases fulfil more than one. In the UK, the professional body is the 
Royal College of Nursing (RCN) and the NMC is the regulator. The RCN also fulfils the role of trades union. Tension between these roles may have contributed to the events at MidStaffordshire, particularly in relation to lack of support for staff, but the RCN rejected Francis' recommendation that the roles be separated (RCN 2013). It is important to keep these different organisational remits in mind when assessing the function of codes in professional practice, since the nature and form of a code depends upon which organisation wrote it and for what purpose.

Codes, generally, are either aspirational or prescriptive (Snelling 2016). Aspirational ethicscodes tend to be written by professional bodies outlining good practice and using descriptive or normative language. Prescriptive codes tend to be codes of conduct, written by regulators outlining minimum standards of practice and using directive language: each clause of the NMC Code starts with 'you must...'. Conduct-codes are quasi-legal in the sense that they are used in fitness to practice proceedings as the benchmark below which conduct is not only blameworthy, but liable to sanction. A good deal of grey separates the black and the white poles of this dichotomy: for example in the US (American Nurses' Association 2015) and Canada (Canadian Nurses Association 2008), codes written by national professional bodies are referred to in hearings by regulators in some states and provinces. In the UK, separation between professional body and regulator is clear and The Code is clearly prescriptive. The difference between these two different sorts of codes and their expectations or requirements is of considerable importance, but there is ambiguity in the NMC Code (Snelling 2017). The paper that presented The Code for approval to the governing Council stated that the '...Code is not an 'aspirational' document but a clear statement of the professional standards everyone should be able to expect from a nurse or midwife.' (NMC 2014, p.3), and yet The Code requires that nurses must: 'Act as a role model of professional behaviour for students and newly qualified nurses to aspire to (NMC 2015, clause 20.8).

The distinction in level between 'just acceptable' and 'good', as related to the issue of compassion is seen elsewhere: Pellegrino and Thomasma's influential book The Virtues in Medical Practice includes, in the chapter on compassion, the following:

Compassion is an essential virtue of medical practice. A good physician does not just apply cognitive data from the medical literature to the particular patient [...]. Rather, the good physician cosuffers with the patient.' 
Compassion is considered both an essential medical virtue as well as one shown by the good doctor. The quotation is embedded in an account that identifies and explains the key medical virtues, which are not concerned with minimal standards of behaviour, but rather encourage doctors and nurses to become actually virtuous. But that is a different thing altogether than requiring virtue, something that the use of compassion in conduct-codes attempts to do.

Regulation for compassion - Professional codes

The version of the Code which impressed Robert Francis was published in 2002. In fact the word 'compassion' cannot be found within it. It states that:

You have a duty of care to your patients and clients, who are entitled to receive safe and competent care (clause 1.4).

[...],You are personally accountable for ensuring that you promote and protect the interests and dignity of patients and clients (clause 2.2).

(NMC 2002)

The 2008 version, developed before the failures in care became nationally prominent introduces the notion of kindness:

You must treat people kindly and considerately (clause 3)

(NMC 2008)

This was the version in operation at the time of the publication of both Francis reports. The latest version confirms that nurses must be kind, but now the word 'compassion' is added on four occasions, including at the start:

You must treat people with kindness, respect and compassion (clause 1.1).

(NMC 2015)

This clause applies to all cases, but there is also reference to the special needs of people as they approach the end of life:

You must recognise and respond compassionately to the needs of those who are in the last few days and hours of life (clause 3.2).

(NMC 2015) 
There has clearly been a shift towards including compassion in the UK code for nursing requiring it of nurses and midwives - that is not required for other professional groups. There is no mention of kindness or compassion in the UK medical regulator's code, though it is seen in other countries' medical codes. UK doctors 'must be polite and considerate', and 'must treat patients as individuals and respect their dignity and privacy' (General Medical Council 2013, clauses 46 and 47). Fifteen other professional groups in the UK are regulated by the Health and Care Professions Council (HCPC), whose code requires that registrants must 'treat service users and carers as individuals, respecting their privacy and dignity'. (Health and Care Professions Council, 2016, clause 1.1). The differences in approach to codified compassion may be a result of the perceived widespread lowering in standards of practice seen in Mid Staffs and elsewhere is a problem particular to nursing, but it also reflects the claims that nursing makes about the nature of its relationship with patients that other professional groups do not. Doctors treat patients, while nurses care for them - and there is a literature on love in nursing (Arman and Rehnsfeldt 2009) rarely seen in literature of other professional groups. The word 'compassion' can be found in most nursing codes around the world, though generally (with some exceptions) more visible in ethics-codes than regulatory conduct-codes (Snelling 2016). The Hong Kong conduct-code does not mention compassion, and in France, the latest country to introduce a conduct-code, nurses are instead required to be conscientious and attentive: 'Ses soins sont consciencieux, attentifs...'. (Ordre National des Infirmiers 2016, Art. R. 4312-10).

These Codes apply to regulated healthcare professionals, who share the feature of being required to be registered with a regulator in order to be able to practice under a legally protected title. Healthcare professionals also are educated for the purpose at (usually) degree level and practice autonomously, supported by a number of subsidiary roles known variously as support workers, carers or assistants. Generally these individuals are not regulated, but Codes of Conduct have been developed. In England, Skills for Health, an organisation committed to workforce development in the health care sector published a code for healthcare support workers in 2013. The Code sets 'the standard expected' but is also voluntary, and seen as 'best practice' (Skills for Health 2016, np). Despite its voluntary status the language is directive and includes: 'you must...always treat people with respect and compassion' (Guidance statement 2, clause 2). The word 'compassion' can be found in a broadly equivalent document in Northern Ireland, but is absent in documents from Wales and Scotland. 
Regulation for compassion: Providers and patients' rights.

An attempt can be made to regulate for compassion in other ways, by requiring providers to provide it, or by regarding it as a patient's right. In New Zealand, a campaign, ultimately unsuccessful, sought to include the right to compassionate care in the Code of Patients' Rights (Paterson 2011). The (broadly) equivalent NHS Constitution sets out the values of the NHS (in England) and the rights of patients, with pledges to meet them. Compassion is claimed as a value of the organisation: 'We ensure that compassion is central to the care we provide...'(Department of Health $[\mathrm{DH}] 2015$, p.5) - but there is no corresponding right. Instead, patients have the right 'to be treated with a professional standard of care, by appropriately qualified and experienced staff' (DH 2015, p.7). A somewhat watered down statement outlines staff responsibilities by stating that 'you should aim to maintain the highest standards of care and service, treating every individual with compassion, dignity and respect' (DH 2015 p.14). So far as nurses are concerned, this could be seen as inconsistent, undercutting the more stringent requirement in their own code; but these responsibilities apply to all staff and the requirement for a compassionate response to patients, is principally part of the nursing narrative of care. The health care regulator, the Care Quality Commission (CQC), assesses whether patients are treated with compassion as part of its inspection routine, largely by observation, talking to patients and documentary review, but it informs the public that the fundamental standards they can expect include that 'You must be treated with dignity and respect at all times while you're receiving care and treatment' (CQC 2017). There is no mention of compassion as a right. So though the word 'compassion' features heavily as a value in policy documents, it is clear that it is not a right of patients, and the only professional group required to treat people with compassion, in the UK, are registered nurses and midwives.

\section{Definition and measurement.}

Leaving discussion of the meaning of compassion until relatively late in this chapter mirrors, to some extent, what happens in health care literature. Paper after paper states that the concept of compassion is undeveloped and yet, like time, it is a word that most people find easy to use but difficult to define or explain. Policy and regulatory documents rarely define it, assuming that we all know what it means. While it may be better to think of features rather than definitions as far as analysis is concerned, there are some different views about the meaning of compassion, notably in relation to other such other-regarding emotions as 
empathy and sympathy (Jeffrey 2016). So while Cole-King and Gilbert's (2011) model highlights compassion and regards empathy as a subordinate albeit required sentiment, Morgan (2016) puts things the other way around, suggesting that compassion should be better thought a component of empathy. Compassion is a complex concept, resisting simple definition.

Surprisingly, there are few studies on what patients regard as compassionate care. In a recent comprehensive scoping review of the literature, Sinclair et al (2016a) identified only two studies (with a sample of patients) which investigate the nature of compassion. The results showed that:

'Compassion was an outcome and a process of intuition and communication, grounded in emotional resonance and a response to suffering predicated on several virtue-based motivators. Seven dimensions associated with compassion were identified: attentiveness, listening, confronting, involvement, helping, presence and understanding'

(Sinclair et al. 2016a, p.4)

This research finding appears consistent with a number of simpler definitions in the literature which regard compassion as consisting of sensitivity to distress in others, along with a commitment to do something about it (for example, Cole-King and Gilbert 2011). Following a detailed review, Strauss et al. (2016) proposed a more detailed definition:

We propose a new definition of compassion as a cognitive, affective, and behavioural process consisting of the following five elements that refer to both self and othercompassion: 1) Recognizing suffering; 2) Understanding the universality of suffering in human experience; 3) Feeling empathy for the person suffering and connecting with the distress (emotional resonance); 4) Tolerating uncomfortable feelings aroused in response to the suffering person (e.g. distress, anger, fear) so remaining open to and accepting of the person suffering; and 5) Motivation to act/acting to alleviate suffering.

(Strauss et al. 2016, p.19)

This account is comprehensive - perhaps too comprehensive - to guide regulation or be measured in individuals, and Strauss et al. proceed in their paper to provide a systematic review that, curiously, does not search nursing academic databases. Nine scales to measure compassion are identified, all of low quality, and they conclude that more testing is required. Development and use of a reliable scale has been a long time coming; plans to measure the quality of compassionate care were announced by the DH in 2008, with the support of the RCN (Bradshaw 2009); but nearly ten years later there has been little progress with this or in 
plans to reward nurses who show compassion. Difficulties of definition and measurement have not prevented the NMC requiring nurses to be compassionate, but no definition is appended to their code. The DH, which bases its nursing strategy on compassion defines it as:

Compassion is how care is given through relationships based on empathy, respect and dignity - it can also be described as intelligent kindness, and is central to how people perceive their care.

(DH 2012, p.13)

So far, I have suggested that the increased profile given to compassion in healthcare, particularly nursing in the UK, has been largely a reaction to recent scandals in care, as part of a government and regulatory response, which - while acknowledging situational causes sees the problem largely in terms of individual shortcomings. The concept of compassion is both complex and under-explored, and - while highly visible in inspection regimes and in values and policy statements - it is not stated explicitly as a patient right. Most health care professions do not require compassion in their registrants, though because of high numbers of nurses, it is required of most healthcare professionals. In the final part of this chapter, however, I will argue that this is an error: compassion cannot be regulated for.

Is compassion really necessary?

The place of compassion in health care is seldom questioned. Rather, it is assumed as sine qua non that compassion is desirable, or even essential. Difficulties of definition obscure this assumption and its precise implications for both 'good' health care practice and minimumlevel regulation. But it can be challenged, though it is important to be clear about different challenging positions, since 'nurses should not be compassionate' and 'nurses need not be compassionate' are both contrary to the codified 'nurses must treat people with compassion'. The first, stronger, claim may be supported by suggesting that empathy (which is required for compassion), and the distress it involves for carers, can detract from the cool reasoning required for effective treatment of patients (Bloom 2016). Saunders (2015) points out that compassion belongs at the patient's bedside rather than in the epidemiologist's office.

However, these two situations represent situations that are not mutually exclusive, and most health care professionals will require cool decision making at the patients' bedside. In the $\mathrm{UK}$, the NMC requires nurses to advocate for individual patients but there is often an opportunity cost to other patients. As an example of the well-known tension between the 
ethics of care and the ethics of justice, it might be argued that undue compassion for a single patient undermines the justice that all deserve and are entitled to.

The second claim is that nurses need not be compassionate. Smajdor (2013) is an unusual voice in arguing that compassion is neither necessary nor sufficient for good health care, suggesting that it is possible to empty a bedpan without caring about the person who has filled it; the operation can may be undertaken with politeness and consideration, but without emotional engagement, even in the face of considerable suffering. An objection might be made that this describes merely adequate rather than good care, but this supports noninclusion of compassion in a conduct-code, since its function is to prescribe only threshold care. Perhaps the best argument that compassion should not, as well as cannot, be (quasilegally) required is that it simply is not morally required.

\section{Defining compassion and its absence.}

Regulatory definitions, while consistent with philosophical and empirical accounts, are difficult to enforce in practice as part of a conduct-code. Disciplinary hearings, however, are more likely to be interested in understanding what the absence of compassion looks like rather than its presence. This might be understood in a number of ways, not all of which are blameworthy. Discussing kindness rather than compassion, Snelling (2016) identifies five types of its absence, firstly where it is simply not called for. There follows a distinction between 'not-being-kind', in the sense of failure to perform a voluntary kind act and being unkind, failure to perform an act which is reasonably required. The fourth category is 'fauxkindness', where an apparently kind act is performed under duress, and the fifth is deliberate malice. A regulator might well be inclined to act against a registrant who failed to perform a required act, and certainly against a malicious act, but in such cases, any wrong against the patient would relate to the badness of the act or its omission, and not because of its failure to be compassionate or kind. One need not require lack of compassion in order to regard malice or thoughtlessness as wrong, or to punish it (Paterson 2010).

\section{Virtues and emotions}

The claim that compassion is a virtue is common in the medical (Pellegrina and Thomasma 1993) and nursing (Armstrong 2007, Sellman 2011) literature. In one of the few studies describing compassion from the patient's point of view, in Canadian patients nearing the end of life, compassion as virtue emerged as a key theme (Sinclair et al. 2016b). But it is worth 
noting that compassion does not feature in Aristotle's account of the virtues (Jones and Pattison 2016). His account of compassion in 'The Art of Rhetoric', (translated as 'pity') as developed by Martha Nussbaum (1996 p.31) is that: '[It] is a painful emotion directed at another's misfortune or suffering', requiring three features. The suffering should be serious, undeserved and the pitier should be able to see the possibility of their own similar suffering. All three would find difficulty in contemporary health care, even if there is some supporting empirical evidence for them. For example, health care professionals are often known to have negative attitudes to those who self-harm (Saunders et al. 2012).

The role of emotions in care is central to feminist and care ethics, which has greatly influenced the field of nursing ethics. There seems to be consensus that a full understanding of compassion includes, to varying extent, both emotional and cognitive elements; but, though emotions are not simply 'knee jerk reactions' (Newham 2016 p.1), neither can they be fully under conscious control. On this ground alone, compassion cannot be mandated, since one cannot require a person to feel something. Recognising compassion as a virtue points to a tension as old as moral theory; while virtue ethics identifies and describes the internal characteristics of agents of good character, it cannot require that they act as virtue prescribes, which is precisely the function of conduct-codes.

\section{Compassion as compliance.}

In contrast to virtues, actions as behaviour can be mandated. But, there is much difference between acting in accordance with a code and complying with it (Spielthenner 2015). Many nurses act compassionately just because they are compassionate and not merely because they are required to. To be sure, sanctions attached to a conduct-code give nurses who are not compassionate a very strong reason for complying with it. While this will not make them compassionate, it can them look as if they are. This is a poor substitute as Wang (2016) points out in relation to the airline industry; we have become used to recognising and discounting enforced emotions, and actions-that-look-like-compassion are, by definition inauthentic. Enforced taxation is not the same as altruistic giving; you can make someone hand over money but this does not make her generous.

\section{Conclusion.}

There is wide consensus, though not unanimity, concerning the place of compassion in good health care practice, particularly in nursing, which has a distinct tradition and philosophy of 
care rather than treatment. There is also consensus that recent events have highlighted that compassion has been lacking, and so a renewed interest on the role of compassion in nursing seems reasonable. But, for reasons I have outlined, compassion is not a quality which can be regulated for, or required of people, and it follows from this is that while it has a place in aspirational ethics-codes, there is no place for it in prescriptive conduct-codes, which as the NMC has stated, need to be written so that compliance is ensured.

I am most certainly not arguing, however, that compassion is not part of, or should not be part of good nursing care, but care at minimum can be delivered without it, if compassion is understood as a virtue requiring emotional engagement. Empathy, on the other hand, is different as Jeffrey (2016, p.450) states: ‘...unlike compassion or sympathy, [it] is not something that just happens to us, it is a choice to make to pay attention to extend ourselves'. Such choice includes treating people with dignity, respect and consideration, and these are words that have a proper place in conduct-codes of health care practitioners. To attempt to require compassion is to misunderstand both the meaning of compassion and the purpose of conduct-codes.

It is easy to be sceptical about the motivation behind current emphasis on the lack of compassion in practitioners in response to the shortcomings of care revealed by Francis and others. The events he described did reveal individual deficiencies of care and the need for greater emphasis on compassion in professional education he recommended serves well to remind us all of our priorities. But Francis also revealed situational factors that were addressed in less detail, including pressures to meet financial targets and staffing shortages. These issues remain (Hewison 2016). Whereas compassion has been subject to regulation, staffing has not; guidance on safe staffing has been issued (NICE 2014), but guidance, unlike standards do not have to be complied with. As I write this in summer 2017, nursing staffing levels in the UK are approaching a perfect storm, with Brexit, an aging workforce, pay erosion, and the introduction of tuition fees for students combining to increase the number of nursing vacancies. In studies of patient and staff perceptions of compassionate care, insufficient time for proper care is identified as a problem (Crawford et al. 2014), and lack of time is exacerbated when staff are short and patients increasingly dependent. Attention to the conditions that enable compassionate care to flourish is sorely needed, and that is a much bigger issue, requiring many more resources that are not currently available. 
$\underline{\text { Dr Paul Snelling }}$

Principal Lecturer in Adult Nursing

University of Worcester

Institute of Health and Society

Henwick Grove

Worcester

WR2 6AJ

ㅇㅛㅛ 01905542615

㖷 p.snelling@worc.ac.uk 


\section{References}

American Nurses Association (2015) Code of Ethics for Nurses. [on line] http://www.nursingworld.org/codeofethics (Accessed 9th July 2017).

Aristotle (1991) The Art of Rhetoric. London: Penguin.

Arman, M., Rehnsfeldt, A. (2006) The presence of love in ethical caring Nursing Forum: 41(1), 4-12.

Armstrong, A.E. (2007) Nursing Ethics: A Virtue Based Approach Basinstoke: Palgrave Macmillan.

Bloom, P. (2016) Against Empathy: The case for rational compassion London: The Bodley Head.

Bradshaw, A. (2009) Measuring nursing care and compassion: the McDonaldised nurse? Journal of Medical Ethics 35(8), 465-468.

Canadian Nurses Association (2008) Code of Ethics for registered Nurses. [on line] https://www.cna-aiic.ca/en/ /media/nurseone/files/en/code_of_ethics_2008_e (Accessed 9th July 2017).

Care Quality Commission (2017) The fundamental standards [on line] https://www.cqc.org.uk/what-we-do/how-we-do-our-job/fundamental-standards (accessed $3^{\text {rd }}$ July 2017).

Cole-King, A., Gilbert, P. (2011). Compassionate care: the theory and the reality. Journal of Holistic Healthcare, 8(3), 29-37.

Crawford, P., Brown, B., Kvangarsnes, M., Gilbert, P. (2014) The design of compassionate care Journal of Clinical Nursing 23(23-24), 3589-3599.

Darley J.M. Batson C.D. (1973) 'From Jerusalem to Jericho': a study of situational and dispositional variables in helping behaviour. Journal of Personality and Social Psychology, 27(1), 100-108.

Department of Health (2012) Compassion in Practice. Nursing Midwifery and Care Staff: Our Vision and Strategy [on line] https://www.england.nhs.uk/wpcontent/uploads/2012/12/compassion-in-practice.pdf (Accessed 9th July 2017).

Department of Health (2015) The NHS Constitution. London: Department of Health [on line] https://www.gov.uk/government/uploads/system/uploads/attachment_data/file/480482 /NHS_Constitution_WEB.pdf (Accessed 9th July 2017).

Kirkup, J. and Holehouse, M. (2012a) David Cameron: There is a real problem with nursing in our hospitals. Daily Telegraph, $6^{\text {th }}$ January 2012. [on line] http://www.telegraph.co.uk/news/health/news/8996771/David-Cameron-There-is-areal-problem-with-nursing-in-our-hospitals.html (accessed 9th July 2017).

Kirkup, J. and Holehouse, M. (2012b) Concerns over care have been 'hidden' to avoid rows, says David Cameron Daily Telegraph, $7^{\text {th }}$ January 2012. [on line] http://www.telegraph.co.uk/news/health/news/8998995/David-Cameron-There-is-areal-problem-with-nursing-in-our-hospitals.html (accessed 9th July 2017). 
Francis, R. (2010) Independent Inquiry into Care Provided by Mid Staffordshire NHS Foundation Trust January 2005 - March 2009. The Stationary Office, London.

Francis, R. (2013) Report of the Mid Staffordshire NHS Foundation Trust Public Inquiry. The Stationary Office, London.

General Medical Council (2013) Good medical practice. London: General Medical Council [on line] http://www.gmc-uk.org/static/documents/content/GMP_.pdf (accessed $9^{\text {th }}$ July 2017).

Gillett, K. (2012) A critical discourse analysis of British national newspaper representations of the academic level of nurse education: too clever for our own good? Nursing Inquiry 19(4), 297-307.

Girvin, J., Jackson, D., Hutchinson, M. (2016) Contemporary public perceptions of nursing: a systematic review and narrative synthesis of the international research evidence. Journal of nursing management 24(8), 994-1006.

Health and Care Professions Council (2016) Standards of conduct, performance and ethics http://www.hcpcuk.org/assets/documents/10004EDFStandardsofconduct,performanceandethics.pdf (accessed $9^{\text {th }}$ July 2017).

Hewison, A. (2016) Compassion in Care: The Policy Response. In Hewison, A., Sawbridge, Y. (eds) (2016) Compassion in Nursing: Theory Evidence and Practice. Basinstoke: Palgrave Macmiallan, Chapter 1, pp 24-42.

International Council of Nurses (2015) Our Mission, Strategic Intent, Core Values and Priorities http://www.icn.ch/who-we-are/our-mission-strategic-intent-core-valuesand-priorities/ (accessed $9^{\text {th }}$ July 2017).

Jeffrey, D. (2016) Empathy, sympathy and compassion in healthcare: Is there a problem? Is there a difference? Does it matter? Journal of the Royal Society of Medicine 109(12), 446-452.

Jones, J., Pattison, S. (2016). Compassion as a Philosophical and Theological Concept. In Hewison, A, and Sawbridge, Y (eds) (2016) Compassion in Nursing: Theory Evidence and Practice Basinstoke: Palgrave Macmillan, Chapter 2, pp 43-56

Morgan, A. (2017). Against compassion: in defence of a "hybrid" concept of empathy. Nursing Philosophy 18(3) e12148. doi:10.1111/nup.12148

National Institute of Health and Care Excellence (2014) Safe staffing for nursing in adult inpatient wards in acute hospitals. [on line] https://www.nice.org.uk/Guidance/SG1 (accessed 9th July 2017).

Newham, R.A. (2017) The emotion of compassion and the likelihood of its expression in nursing practice. Nursing Philosophy, 18(3) e12163. doi:10.1111/nup.12163

Nursing and Midwifery Council (2002) Code of Professional Conduct. London: Nursing and Midwifery Council

Nursing and Midwifery Council (2008). The Code: Standards of conduct, performance and ethics for nurses and midwives. London: Nursing and Midwifery Council 
Nursing and Midwifery Council (2013) NMC response to the Francis report. London: NMC, http://www.nmc.org.uk/globalassets/siteDocuments/Francis-report/NMC-response-tothe-Francis-report-18-July.pdf (accessed ${ }^{\text {th }}$ July 2017).

Nursing and Midwifery Council (2014) Standards and guidance review cycle 2014/2017. Presented in board papers for council meeting 26th March 2014, item 10, pp 111-112 https://www.nmc.org.uk/globalassets/sitedocuments/councilpapersanddocuments/cou ncil-2014/council-papers-20141203-final-pdf.pdf (accessed $9^{\text {th }}$ July 2017).

Nursing and Midwifery Council (2015). The code: standards of conduct performance and ethics for nurses and midwives. London: NMC, http://www.nmc.org.uk/globalassets/sitedocuments/standards/the-code-a420100406.pdf (accessed $9^{\text {th }}$ July 2017).

Nussbaum, M. (1996) Compassion: The basic social emotion. Social Philosophy and Policy, 13(1), 27-58.

Ordre National des Infirmiers (2016) Code de deontoloogie des infirmiers [on line] https://www.ordre-infirmiers.fr/deontologie/publication-du-code-de-deontologie.html (accessed $9^{\text {th }}$ July 2017).

Paley, J. (2014) Cognition and the compassion deficit: the social psychology of helping behaviour in nursing. Nursing Philosophy, 15(4), 274-287.

Paterson, R. (2010). Regulating for compassion. Journal of Law and Medicine 18, 58-67.

Paterson, R. (2011). Can we mandate compassion? Hastings Center Report 41(2), 20-23.

Pellegrino, E.D., Thomasma, D.C. (1993). The Virtues in Medical Practice. New York, Oxford University Press.

Rolfe, G., Gardner, L.D. (2014). The compassion deficit and what to do about it: a response to Paley. Nursing Philosophy 15(4), 288-297.

Royal College of Nursing Royal College of Nursing (2013) Mid Staffordshire NHS Foundation Trust Public Inquiry Report: Response of the Royal College of Nursing. [on line] https://my.rcn.org.uk/_data/assets/pdf_file/0010/530956/004476.pdf (accessed 9th July 2017)

Saunders, J. (2015) Compassion. Clinical Medicine, 15(2), 121-124.

Saunders, K. E., Hawton, K., Fortune, S., Farrell, S. (2012) Attitudes and knowledge of clinical staff regarding people who self-harm: a systematic review. Journal of affective disorders, 139(3), 205-216.

Sellman, D. (2011) What Makes a Good Nurse: Why the Virtues are Important for Nurses. Jessica Kingsley, London.

Simons D.J., Chabris C.F. (1999) Gorillas in our midst: sustained inattention blindness for dynamic events. Perception 28, 1059-1074.

Sinclair, S., Norris, J. M., McConnell, S. J., Chochinov, H. M., Hack, T. F., Hagen, et al. (2016a). Compassion: a scoping review of the healthcare literature. BMC palliative care, 15(1), 6 . 
Sinclair, S., McClement, S., Raffin-Bouchal, S., Hack, T. F., Hagen, N. A., McConnell, S., \& Chochinov, H. M. (2016b). Compassion in health care: An empirical model. Journal of pain and symptom management, 51(2), 193-203.

Skills for health (2016) Code of Conduct for healthcare support workers and adult social care workers [on line] http://www.skillsforhealth.org.uk/standards/item/217-code-ofconduct (accessed 14th July 2017).

Smajdor, A. (2013) Reification and compassion in medicine: A tale of two systems. Clinical Ethics, 8(4), 111-118.

Snelling, P.C. (2013) Ethical and professional concerns in research utilisation: intentional rounding in the United Kingdom. Nursing Ethics, 20(7), 784-797.

Snelling, P.C. (2016) The metaethics of nursing codes of ethics and conduct. Nursing Philosophy, 17(4), 229-249.

Snelling, P.C. (2017) Can the revised UK code direct practice? Nursing Ethics, 24(4),392407.

Spielthenner, G. (2015) Why comply with a code of ethics? Medicine, Health Care and Philosophy, 18(2), 195-202.

Strauss, C., Taylor, B. L., Gu, J., Kuyken, W., Baer, R., Jones, F., \& Cavanagh, K. (2016). What is compassion and how can we measure it? A review of definitions and measures. Clinical Psychology Review, 47, 15-27.

Traynor, M., Stone, K., Cook, H., Gould, D., \& Maben, J. (2014) Disciplinary processes and the management of poor performance among UK nurses: bad apple or systemic failure? A scoping study. Nursing inquiry, 21(1), 51-58.

Wang, Y. (2016) Smiling through clenched teeth: why compassion cannot be written into the rules. Journal of Medical Ethics, 42:7-9. 